\title{
Formulation and in vitro Assessment of Eudragit $L 100$ and Eudragit S 100 Based Naproxen Microspheres
}

\author{
Md. Ataur Rahman ${ }^{1}$, Nusrat Ahmed ${ }^{1}$, Ikramul Hasan ${ }^{2}$ and Md. Selim Reza ${ }^{2}$ \\ ${ }^{1}$ Department of Pharmacy, University of Asia Pacific, 74/A, Green Road, Dhaka-1215, Bangladesh. \\ ${ }^{2}$ Department of Pharmaceutical Technology, Faculty of Pharmacy, University of Dhaka, \\ Dhaka-1000, Bangladesh.
}

Received: May 16, 2016; Accepted: June 03, 2016; Published (web): June 20, 2016

\begin{abstract}
In the present study naproxen loaded microspheres were prepared by emulsification solvent evaporation method in order to achieve targeted drug delivery. Eudragit L 100 and Eudragit S 100 were used as the rate retardant polymers in the preparations. Thirteen formulations (F1-F13) were prepared using $2^{2}$ factorial design by changing the concentration of these two polymers. All the formulations were evaluated for product yield, drug content, entrapment efficiency, particle size and drug release profiles. Highest drug content and entrapment efficiency were found to be $30.17 \%$ (F4) and $91.86 \%$ (F8) respectively. The particle size was found to be $159.26-234.70 \mu \mathrm{m}$ for all formulations. In-vitro drug release studies were performed using USP type II (Paddle) apparatus for $8 \mathrm{hrs} \mathrm{in} \mathrm{pH}$ 7.4 phosphate buffer. The maximum drug release after $8 \mathrm{hrs}$ was found to be $60.19 \%$ for batch $\mathrm{F} 4$. The release kinetics of all formulations were evaluated by using zero order, first order, Higuchi, Korsmeyer-Peppas, Kopcha and Hixson Crowell model. Almost all formulations fitted best with the Kopcha kinetic model. The SEM study indicated the spherical structure of the microspheres having rough surfaces.
\end{abstract}

Key words: Microspheres, Naproxen, Eudragit L 100, Eudragit S 100, Emulsification Solvent Evaporation.

\section{INTRODUCTION}

Microspheres act as advanced drug delivery system where the particle size ranges from 1-1000 $\mu \mathrm{m}$. Microspheres can be divided into two groups, namely microcapsules and microspheres. ${ }^{1}$ Microcapsules are reservoir type drug delivery system, in which the outer surface of the drugs are covered by layer of a polymeric membrane. On the other hand, microspheres are spherical matrix type drug delivery system. ${ }^{2}$ Microspheres act as a good candidate for controlled or sustained drug delivery system from which the drugs are released by diffusion and/or erosion mechanisms. ${ }^{3}$

Naproxen, a nonsteroidal anti-inflammatory drug, is widely used in the treatment of rheumatoid arthritis, osteoarthritis, juvenile arthritis, ankylosing spondylitis, tendinitis, bursitis, acute gout and primary dysmenorrhoea. Plasma protein binding

Correspondence to: Md. Selim Reza

Tel: +880-2-8612069, Fax: +880-28615583

E-mail: selim.du@gmail.com

Dhaka Univ. J. Pharm. Sci. 15(1): 47-55, 2016 (June) capacity of naproxen is relatively high and these properties refer to formulate sustained release drug delivery system. ${ }^{4}$

Eudragit L 100 and Eudragit S 100 are anionic copolymers based on methacrylic acid and methyl methacrylate. The targeted drug release area attained by Eudragit L 100 is jejunum, which releases the drug above $\mathrm{pH} 6.0$ and the targeted drug release area for Eudragit S 100 is colon, which releases the drug above $\mathrm{pH}$ 7.0. Combination of these two polymers will allow the release the drug all throughout the intestine for a prolonged period. ${ }^{5}$ So they are good candidates for incorporating into microsphere formulations as targeted release retardants.

The emulsification solvent evaporation technique has been widely used in the preparation of polymeric microspheres. This process is most suitable for insoluble or poorly soluble drugs in the aqueous medium. Factors that can influence the behavior of the microspheres are, drug solubility, internal and external morphology, solvent type, diffusion rate, 
temperature, polymer composition and viscosity, particle size and drug loading. ${ }^{6}$

\section{MATERIALS AND METHODS}

Naproxen was collected from Beximco Pharmaceuticals limited, Bangladesh as a gift sample. All other ingredients were of BP, USP pharmaceutical grade and purchased from the local market.

Preparation of naproxen loaded microspheres of Eudragit L 100 and Eudragit S 100 polymeric blend. Sustained release microspheres containing naproxen was prepared by emulsification solvent evaporation method. The drug and polymer were dissolved in a mixture of $10 \mathrm{ml}$ acetone and $5 \mathrm{ml}$ methanol. The resulting solution was poured drop wise at constant rate to $70 \mathrm{ml}$ of liquid paraffin containing $0.7 \mathrm{ml}$ Span 80 in a $250 \mathrm{ml}$ beaker under magnetic stirring at $1000 \mathrm{rpm}$ to disperse the added mixture as fine droplets. The system was stirred for 2 hrs to evaporate the solvent at room temperature which produce the microspheres of naproxen suspended in liquid paraffin. The prepared microspheres were collected by filtration and washed with n-hexane. Finally, the prepared microspheres were dried at room temperature and stored in well closed containers. $^{7,8}$

Formulation design. In this present study, formulations of naproxen loaded polymeric blend of microspheres were designed according to $2^{2}$ factorial central composite design. ${ }^{9}$ Total thirteen batches (F1F13) were prepared as shown in Table 1.

Table 1. Formulation of naproxen loaded polymeric blend of microspheres.

\begin{tabular}{ccccc}
\hline Formulation Code & Naproxen $(\mathrm{mg})$ & Eudragit L 100 $(\mathrm{mg})$ & Eudragit S 100 $(\mathrm{mg})$ & Drug : Polymer Ratio \\
\hline F1 & 500 & 1000 & 750 & $1: 3.5$ \\
F2 & 500 & 1000 & 250 & $1: 2.5$ \\
F3 & 500 & 500 & 750 & $1: 2.5$ \\
F4 & 500 & 500 & 250 & $1: 1.5$ \\
F5 & 500 & 396.45 & 500 & $1: 1.79$ \\
F6 & 500 & 1103.55 & 500 & $1: 3.21$ \\
F7 & 500 & 750 & 146.45 & $1: 1.79$ \\
F8 & 500 & 750 & 853.55 & $1: 3.21$ \\
F9 & 500 & 750 & 500 & $1: 2.5$ \\
F10 & 500 & 750 & 500 & $1: 2.5$ \\
F11 & 500 & 750 & 500 & $1: 2.5$ \\
F12 & 500 & 750 & 500 & $1: 2.5$ \\
F13 & 500 & 750 & 500 & $1: 2.5$ \\
\hline
\end{tabular}

Determination of percentage yield. The microspheres were dried and weighed. Yield (\%) of the microspheres were calculated using the following equation. $^{10}$

Percentage yield $=($ Practical yield $/$ Theoretical yield $)$ $\times 100$

Determination of drug content and entrapment efficiency. ${ }^{11} 50 \mathrm{mg}$ microspheres were crushed in a mortar and fine powder obtained was taken in a $50 \mathrm{ml}$ volumetric flask. $5 \mathrm{ml}$ methanol was added into the volumetric flask and sonicated for about 10 minutes until the drug and polymer were dissolved. Then, the final volume was adjusted up to
$50 \mathrm{ml}$ by using $\mathrm{pH} 7.4$ phosphate buffer. The resultant solutions were filtered, and after suitable dilution their absorbances were measured by ultraviolet spectrophotometer at $332 \mathrm{~nm} .^{12}$

Particle size analysis. ${ }^{13}$ The particle sizes of the prepared naproxen loaded microspheres were measured by using Mastersizer (2000) laser diffraction analyzer. $50 \mathrm{mg}$ of prepared microspheres were dispersed in $5 \mathrm{ml}$ of distilled water containing $2 \% \mathrm{w} / \mathrm{v}$ of Tween 80 , to prevent agglomeration of the microspheres. The dispersions were sonicated in water bath and the particle size was expressed as volume mean diameter in micrometer. Average particle size $(\mu \mathrm{m})$ of microspheres were indicated by 
the volume mean diameter $\mathrm{D}[4,3] .{ }^{14}$ Span index was calculated by using following equation.

$$
\text { Span index }=\mathrm{D}(0.9)-\mathrm{D}(0.1) / \mathrm{D}(0.5)
$$

Where, D (0.9), D (0.5) and D (0.1) particle diameters determined at $90^{\text {th }}, 50^{\text {th }}$ and $10^{\text {th }}$ percentile of particles respectively. ${ }^{15}$

In vitro drug release studies in $\mathbf{p H} 7.4$ phosphate buffer. In-vitro dissolution study was performed with USP type II (paddle) dissolution apparatus. Dissolution was performed for $8 \mathrm{hrs}$ in basic medium (pH 7.4 phosphate buffer). $50 \mathrm{mg}$ of microspheres were taken from each formulation and transferred into dissolution basket which was previously filled with $900 \mathrm{ml}$ of $\mathrm{pH} 7.4$ phosphate buffer; Paddle speed was fixed at $50 \mathrm{rpm}$ at $37 \pm$ $0.5^{\circ} \mathrm{C} .10 \mathrm{ml}$ dissolution sample was withdrawn at predetermined time intervals (15 minutes, 30 minutes, 1 hour, 2 hrs, 3 hrs, 4 hrs, 5 hrs, 6 hrs, 7 hrs and $8 \mathrm{hrs}$ ) from each dissolution basket. The dissolution medium was compensated with fresh refills after each sample withdrawals to keep the volume constant. Then, the withdrawn dissolution samples were sonicated few seconds for proper mixing, filtered and analyzed spectrophotometrically at $332 \mathrm{~nm}$. The dissolution study for each formulation was performed in triplicate and the average values were calculated.
Surface morphology study by scanning electron microscope. External surface characteristics of the prepared naproxen loaded microspheres were studied by scanning electron microscopy. The selected samples of microspheres were coated with a double sided sticking tape, sealed and finally coated with gold under reduced pressure for 15 minutes using ion sputtering device and scanned with scanning electron microscope using Hitachi S3400N instrument. Finally, photomicrographs of the samples were recorded under different magnification.

\section{RESULTS AND DISCUSSION}

Physicochemical characteristics of naproxen loaded microspheres formulations.

The yields of the formulations were found to be 98.29\% and $75.47 \%$ for $\mathrm{F} 12$ and $\mathrm{F} 1$ respectively. Greater amount of polymer concentration gave more entrapment efficiency and lower polymer concentration reduced the percent entrapment efficiency. ${ }^{16}$ Therefore the entrapment efficiency of batch F6 and F8 were found to be more than other batches which were, $89.05 \%$ and $91.86 \%$ respectively. On the other hand, the entrapment efficiency of batch F13 was found to be low (74.66\%) which contains drug and polymer ratio of 1 : 2.5. The drug content of batch F4 was $30.17 \%$ due to the presence of lower amount of polymer (Table 2).

Table 2. Percentage yield, actual drug content (\%), theoretical drug content (\%) and entrapment efficiency of naproxen loaded micrioparticles formulations (F1 - F13).

\begin{tabular}{ccccc}
\hline Formulation code & $\begin{array}{c}\text { Yield } \\
(\%)\end{array}$ & $\begin{array}{c}\text { Actual drug content } \\
(\%)\end{array}$ & $\begin{array}{c}\text { Theoretical drug content } \\
(\%)\end{array}$ & $\begin{array}{c}\text { Entrapment efficiency } \\
(\%)\end{array}$ \\
\hline F1 & 75.47 & 18.67 & 22.22 & 84.00 \\
F2 & 90.29 & 22.50 & 28.57 & 78.75 \\
F3 & 89.71 & 24.00 & 28.57 & 84.00 \\
F4 & 80.80 & 30.17 & 40.00 & 75.42 \\
F5 & 90.94 & 27.67 & 35.81 & 77.27 \\
F6 & 96.50 & 21.17 & 23.77 & 89.05 \\
F7 & 96.67 & 29.83 & 35.81 & 83.32 \\
F8 & 94.13 & 21.83 & 23.77 & 91.86 \\
F9 & 94.29 & 23.00 & 28.57 & 80.50 \\
F10 & 88.57 & 22.17 & 28.57 & 77.58 \\
F11 & 84.57 & 23.00 & 28.57 & 80.50 \\
F12 & 98.29 & 21.50 & 28.57 & 75.25 \\
F13 & 96.57 & 21.33 & 28.57 & 74.67 \\
\hline
\end{tabular}


Table 3. Particle size $(\mu \mathrm{m})$ distribution parameters of naproxen loaded microspheres formulations (F1 - F13).

\begin{tabular}{cccccc}
\hline Formulation code & $\mathrm{D}(0.1)$ & $\mathrm{D}(0.5)$ & $\mathrm{D}(0.9)$ & Span & $\begin{array}{c}\text { Volume Weighted Mean } \\
\mathrm{D}[4,3]\end{array}$ \\
\hline F1 & 166.74 & 234.10 & 329.25 & 0.69 & 242.44 \\
F2 & 166.73 & 234.10 & 329.25 & 0.69 & 242.44 \\
F3 & 143.78 & 218.47 & 330.93 & 0.86 & 229.31 \\
F4 & 162.03 & 225.69 & 310.90 & 0.66 & 237.71 \\
F5 & 162.20 & 226.41 & 316.64 & 0.68 & 234.32 \\
F6 & 110.42 & 176.74 & 266.18 & 0.88 & 180.77 \\
F7 & 160.25 & 222.63 & 308.99 & 0.67 & 229.83 \\
F8 & 148.37 & 213.61 & 308.28 & 0.75 & 222.19 \\
F9 & 113.17 & 154.68 & 212.28 & 0.64 & 159.26 \\
F10 & 101.23 & 160.26 & 228.14 & 0.79 & 159.79 \\
F11 & 113.17 & 154.68 & 212.28 & 0.64 & 159.26 \\
F12 & 110.42 & 176.74 & 266.18 & 0.88 & 180.77 \\
F13 & 143.78 & 218.47 & 330.93 & 0.86 & 229.31 \\
\hline
\end{tabular}

The particle size was expressed as the volume weighted mean in micrometers. ${ }^{17}$ The particle size $(\mu \mathrm{m})$ of all batches ranged between 159.26-234.70 $\mu \mathrm{m}$ (Table 3). Higher span index indicates the high level of non-uniformity and its value is used to characterize the microspheres as monodisperse, homogenous and heterogeneous systems. Lowest value of span index was found for batch F9 and F11 which indicated that, the particle sizes were monodispersed. The highest value of span index was found for batch F6 and F12 which was 0.881. Here, $\mathrm{D}(0.5)$ is the size of particles at which $50 \%$ of the sample is smaller and $50 \%$ is larger than this size. D $(0.1)$ is the size of particles for which $10 \%$ of the sample is below this size. $\mathrm{D}(0.9)$ indicates the size of particles for which $90 \%$ of the sample is below this size.

In vitro release kinetics of naproxen loaded microspheres formulations. At first hour the drug release was found ranged from 14.09 to $25.70 \%$ for all formulations. Initial burst release occurred because the drug may be present on the surface of particles. After the first hour the drugs were released very slowly. Consequently the descending release order was $\mathrm{F} 4>\mathrm{F} 7>\mathrm{F} 5>\mathrm{F} 11>\mathrm{F} 13>\mathrm{F} 12>\mathrm{F} 9>\mathrm{F} 10>\mathrm{F} 3>$ $\mathrm{F} 8>\mathrm{F} 6>\mathrm{F} 2>\mathrm{F} 1$. The highest drug release $60.19 \%$ was found for formulation F4 after $8 \mathrm{hrs}$ because F4 contains lower polymer concentration (60\%). On the other hand, the lowest drug release $30.65 \%$ was found for formulation F1 after $8 \mathrm{hrs}$ as F1 contains higher polymer concentration (77.78\%).

The drug release characteristics from F1, F2, F3, F5, F6, F8, F9, F10, F11 and F13 formulations were fitted best to Kopcha kinetic model due to higher value of regression coefficient $\left(\mathrm{R}^{2}\right)$ of $0.983,0.993$, $0.975,0.994,0.994,0.983,0.986,0.981,0.986$ and 0.976 respectively (Table $4 \& 5$ ). Formulations F4, F7 and F12 were fitted best to Higuchi, Higuchi and Korsmeyer-Peppas and Higuchi and Kopcha model respectively due to higher value of regression coefficients $\left(\mathrm{R}^{2}\right)$. The value of diffusion exponent (n) was found to be ranged between 0.369 to 0.044 for F1, F2, F3, F5, F6, F9, F10, F11, F12 and F13 formulations which are responsible for Fickian diffusion. On the other hand, the exponent value (n) of F4, F7 and F8 formulations were found to be ranged between 0.450 to 0.575 which are responsible for anomalous or non-Fickian diffusion. The Kopcha kinetics model used to determine diffusional and erosional drug release. Fickian diffusion occurs when diffusion constant (A) is greater than erosional constant (B). The value of diffusional constant was found to be ranged from 13.75 to 28.92 and erosional constant ranged from (-5.891 to 2.270) for all formulations. Diffusional constant values were greater than erosional constant values for all formulations which suggested that the drug release occurred by Fickian diffusion. 

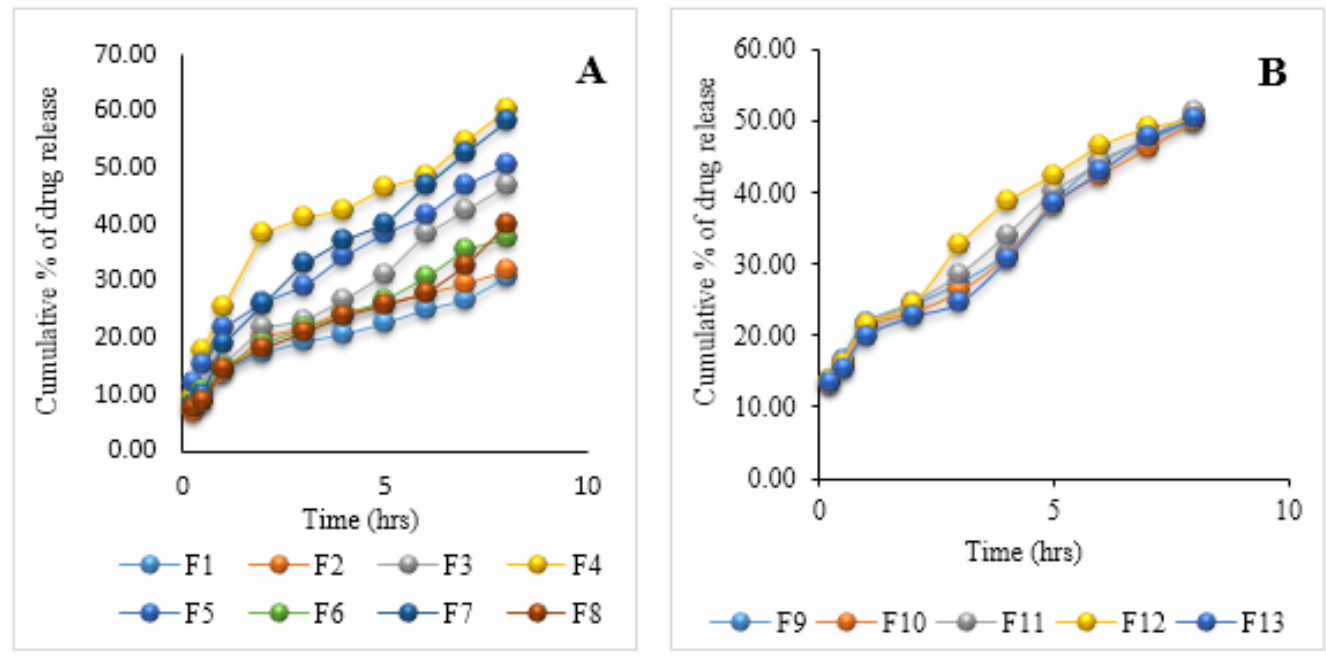

Figure 1. Comparative zero order plot of all formulations, A. F1-F8, B. F9-F13.
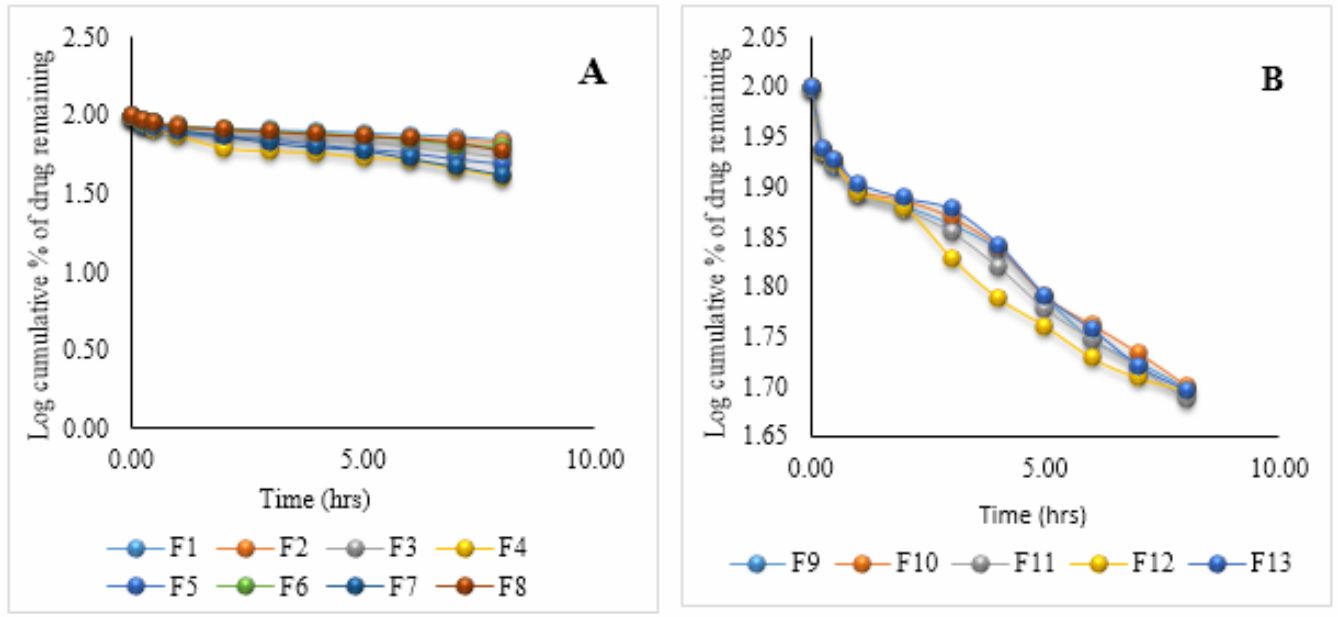

Figure 2. Comparative first order plot of all formulations, A. F1-F8, B. F9-F13.
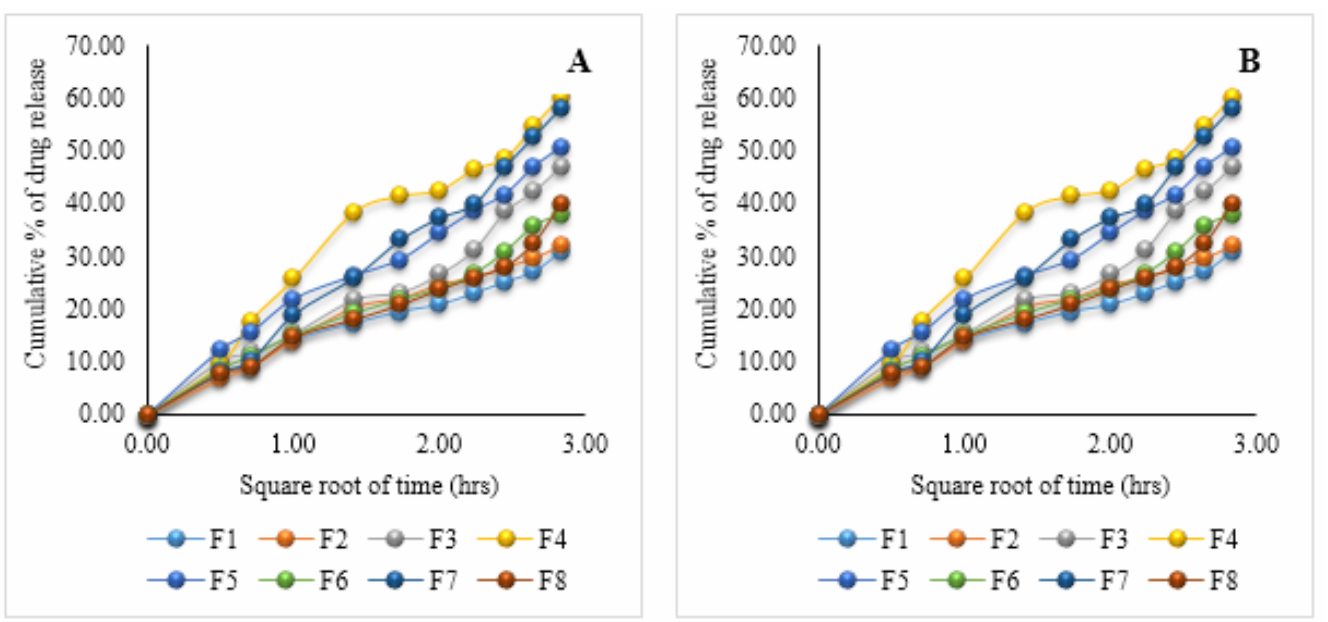

Figure 3. Comparative Higuchi plot of all formulations, A. F1-F8, B. F9-F13. 

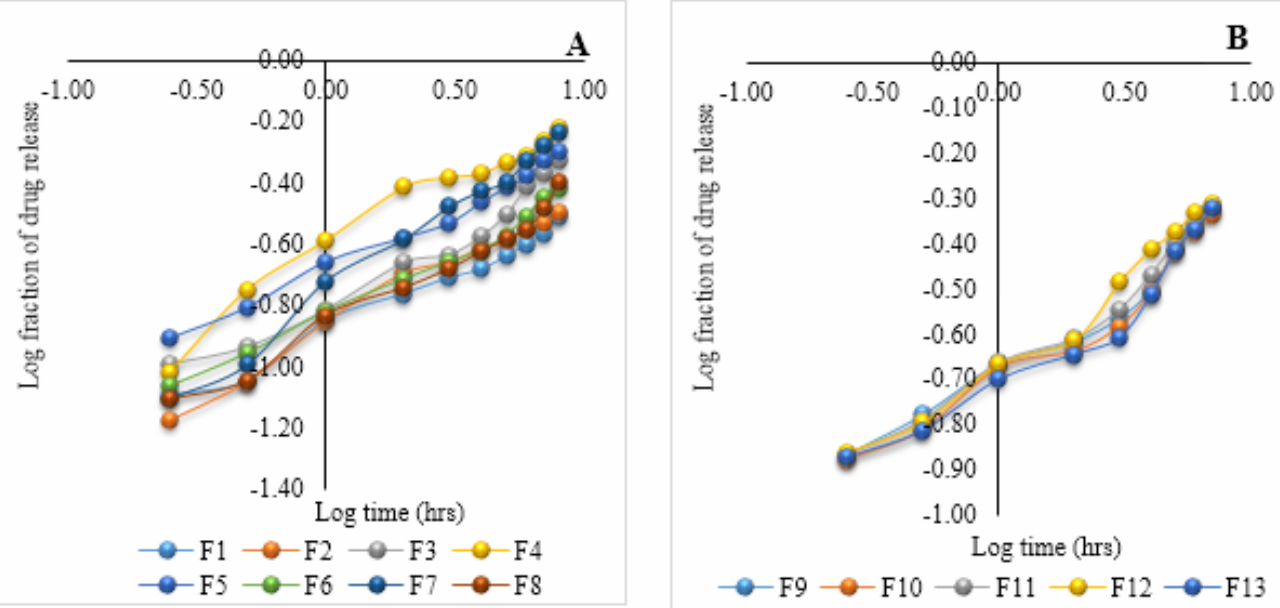

Figure 4. Comparative Korsmeyer-Peppas plot of all formulations, A. F1-F8, B. F9-F13.
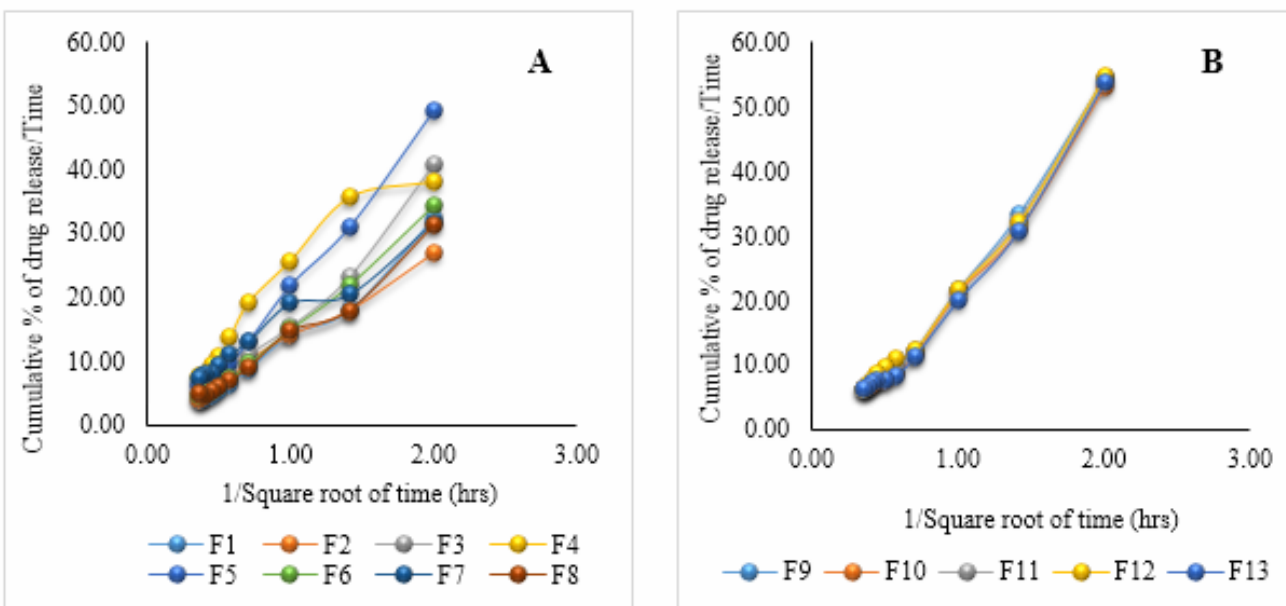

Figure 5. Comparative Kopcha plot of all formulations, A. F1-F8, B. F9-F13.
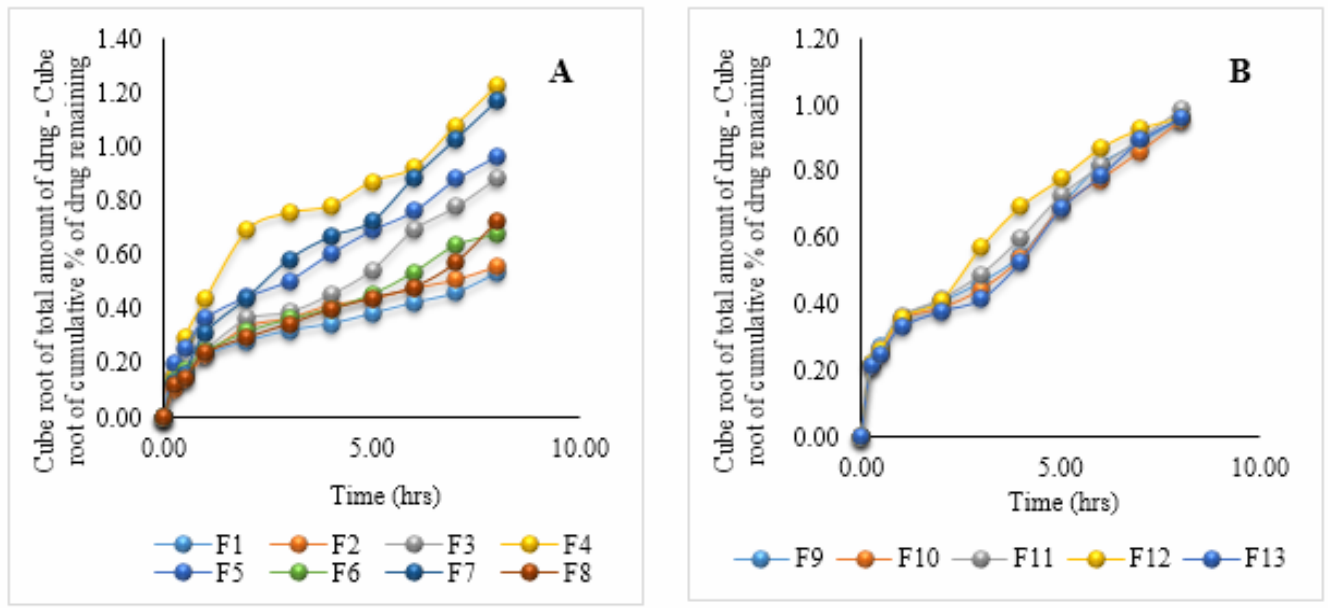

Figure 6. Comparative Hixson Crowell plot of all formulations, A. F1-F8, B. F9-F13. 
Interpretation of $\mathbf{R}^{2}$ values, release rate constants of naproxen Microspheres.

Table 4. $R^{2}$ values, release rate constants of naproxen microspheres for F1-F7 formulations.

\begin{tabular}{|c|c|c|c|c|c|c|c|c|}
\hline \multirow[b]{2}{*}{ Kinetic Model } & \multirow[b]{2}{*}{ Parameter } & \multicolumn{7}{|c|}{ Formulation Code } \\
\hline & & $\mathrm{F} 1$ & F2 & F3 & F4 & F5 & F6 & F7 \\
\hline \multirow[t]{2}{*}{ Zero order } & $\mathrm{R}^{2}$ & 0.884 & 0.866 & 0.957 & 0.858 & 0.917 & 0.931 & 0.957 \\
\hline & $\mathrm{K}_{0}$ & 3.018 & 3.394 & 5.011 & 6.252 & 5.219 & 3.959 & 6.582 \\
\hline \multirow[t]{2}{*}{ First order } & $\mathrm{R}^{2}$ & 0.913 & 0.898 & 0.972 & 0.923 & 0.960 & 0.956 & 0.983 \\
\hline & $\mathrm{K}_{1}$ & -0.034 & -0.041 & -0.066 & -0.096 & -0.073 & -0.050 & -0.099 \\
\hline \multirow[t]{2}{*}{ Higuchi } & $\mathrm{R}^{2}$ & 0.979 & 0.982 & 0.971 & 0.971 & 0.988 & 0.983 & 0.991 \\
\hline & $\mathrm{K}_{\mathrm{H}}$ & 9.62 & 10.95 & 15.30 & 20.16 & 16.42 & 12.33 & 20.31 \\
\hline \multirow{3}{*}{$\begin{array}{l}\text { Korsmeyer- } \\
\text { Peppas }\end{array}$} & $\mathrm{R}^{2}$ & 0.982 & 0.985 & 0.962 & 0.958 & 0.989 & 0.984 & 0.991 \\
\hline & $\mathrm{K}_{\mathrm{KP}}$ & 0.130 & 0.130 & 0.163 & 0.228 & 0.207 & 0.146 & 0.171 \\
\hline & $\mathrm{n}$ & 0.375 & 0.444 & 0.440 & 0.477 & 0.394 & 0.412 & 0.575 \\
\hline \multirow[t]{3}{*}{ Kopcha } & $\mathrm{R}^{2}$ & 0.983 & 0.993 & 0.975 & 0.934 & 0.994 & 0.994 & 0.978 \\
\hline & A & 16.76 & 13.75 & 20.49 & 20.78 & 25.94 & 17.99 & 14.43 \\
\hline & $\mathrm{B}$ & -2.935 & -0.662 & -3.030 & 1.386 & -4.064 & -2.554 & 2.270 \\
\hline \multirow[t]{2}{*}{ Hixson-Crowell } & $\mathrm{R}^{2}$ & 0.905 & 0.888 & 0.969 & 0.905 & 0.948 & 0.950 & 0.978 \\
\hline & $\mathrm{K}_{\mathrm{HC}}$ & 0.053 & 0.060 & 0.095 & 0.129 & 0.102 & 0.072 & 0.133 \\
\hline
\end{tabular}
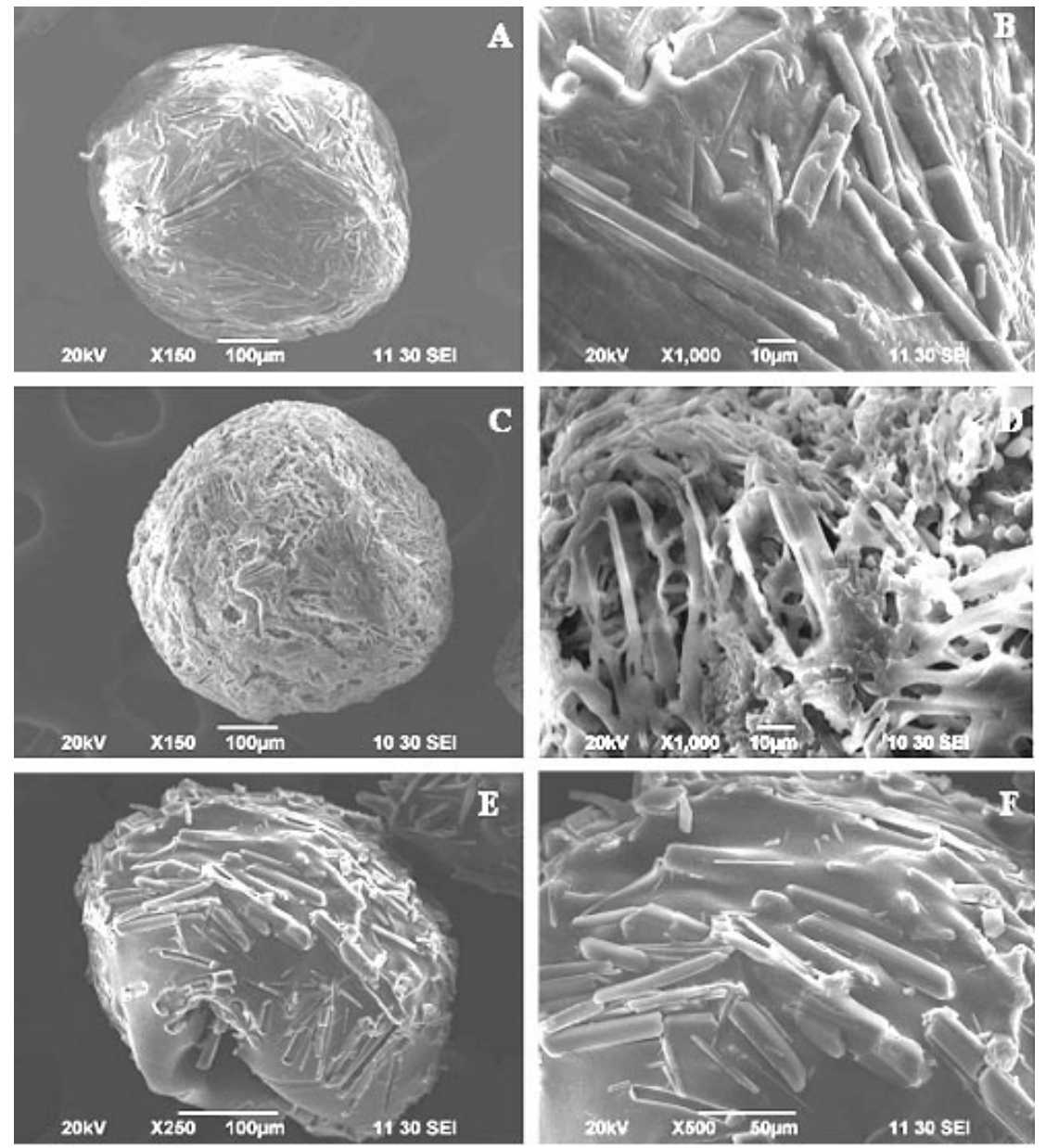

Figure 7. SEM image of different formulations, A. Formulation F1 (at X150 magnification), B. Formulation F1 (at X1000 magnification),

C. Formulation F1 (after 4 hrs dissolution at X150 magnification), D. Formulation F1 (after 4 hrs dissolution at X1000 magnification),

E. Formulation F4 (at X250 magnification), F. Formulation F4 (at X500 magnification). 
Table 5. $\mathbf{R}^{2}$ values, release rate constants of naproxen microspheres for F8-F13 formulations.

\begin{tabular}{|c|c|c|c|c|c|c|c|}
\hline \multirow[b]{2}{*}{ Kinetic Model } & \multirow[b]{2}{*}{ Parameter } & \multicolumn{6}{|c|}{ Formulation Code } \\
\hline & & F8 & F9 & F10 & F11 & F12 & F13 \\
\hline \multirow[t]{2}{*}{ Zero order } & $\mathrm{R}^{2}$ & 0.934 & 0.925 & 0.930 & 0.928 & 0.909 & 0.940 \\
\hline & $\mathrm{K}_{0}$ & 3.978 & 5.238 & 5.185 & 5.375 & 5.527 & 5.345 \\
\hline \multirow[t]{2}{*}{ First order } & $\mathrm{R}^{2}$ & 0.948 & 0.960 & 0.963 & 0.966 & 0.954 & 0.966 \\
\hline & $\mathrm{K}_{1}$ & -0.050 & -0.073 & -0.073 & -0.078 & -0.080 & -0.076 \\
\hline \multirow[t]{2}{*}{ Higuchi } & $\mathrm{R}^{2}$ & 0.970 & 0.973 & 0.972 & 0.983 & 0.989 & 0.965 \\
\hline & $\mathrm{K}_{\mathrm{H}}$ & 12.29 & 16.29 & 16.07 & 16.78 & 17.47 & 16.42 \\
\hline \multirow[t]{3}{*}{ Korsmeyer-Peppas } & $\mathrm{R}^{2}$ & 0.976 & 0.956 & 0.951 & 0.970 & 0.979 & 0.933 \\
\hline & $\mathrm{K}_{\mathrm{KP}}$ & 0.134 & 0.211 & 0.203 & 0.213 & 0.217 & 0.200 \\
\hline & $\mathrm{n}$ & 0.445 & 0.369 & 0.376 & 0.381 & 0.398 & 0.383 \\
\hline \multirow[t]{3}{*}{ Kopcha } & $\mathrm{R}^{2}$ & 0.983 & 0.986 & 0.981 & 0.986 & 0.982 & 0.976 \\
\hline & A & 15.67 & 28.92 & 27.91 & 28.58 & 28.27 & 27.94 \\
\hline & B & -1.669 & -5.891 & -5.651 & -5.496 & -4.967 & -5.832 \\
\hline
\end{tabular}

Surface morphology study by Scanning Electron Microscope (SEM). Naproxen loaded microspheres of formulation $\mathrm{F} 1$ was observed spherical in shape but surface was not smooth. However after $4 \mathrm{hrs}$ of dissolution, number of sieve or channel like structure was observed in formulation F1 which were confirmed at different magnification. Microspheres of formulation F4 was irregular in shape and surface was not smooth. Plate or rod shaped particles of naproxen were found onto the surface of the microspheres. This was confirmed by dissolution test when initial burst release was observed within 15 minutes. This initial release of drug would help to provide a therapeutic dose soon after administration.

\section{CONCLUSIONS}

Naproxen loaded polymeric blend of microspheres were prepared by emulsification solvent evaporation technique using magnetic stirrer. The method was easy, cheap, simple and reproducible. This study showed that polymeric blend of Eudragit L 100 and Eudragit S 100 microspheres could be useful carrier for naproxen. Formulation F4 can be considered as the best formulation than other formulation because of higher release of drug after 8 hrs. Dissolution data of formulation F4 best fitted the Higuchi kinetics model following Fickian diffusion mechanism. However, widespread research including in-vivo experimentation is required for enhancing its future applications.

\section{REFERENCES}

1. Komatsu, M., Tagawa, K., Kawata M. and Goto, S. 1983. Biopharmaceutical evaluation of gelatin microcapsules of sulfonamides. Chem. Pharm. Bull. 31, 262-268.

2. Li, S.P., Kowalski, C.R., Feld, K.M. and Grim, W.M. 1988. Recent advances in microencapsulation technology and equipment. Drug Dev. Ind. Pharm. 14, 353-376.

3. Illum, L., Furraj, N.F., Critcheley, H. and Davis, S.S. 1988. Nasal administration of gentamycin using a novel microsphere delivery system. Int. J. Pharm. 46, 261-265.

4. Zaghloul, A.A., Faltinek, J., Vaithiyalingam, S.R., Reddy, I.K. and Khan, M.A. 2001. Screening of process and formulation variables for the preparation of extended release tablets of Naproxen-Eudragit microspheres. Pharmazie 56, 321-324.

5. Khan, M., Štedul, H. and Kurjaković, N. 2000. A pHdependent colon-targeted oral drug delivery system using methacrylic acid copolymers. II. Manipulation of drug release using Eudragit ${ }^{\circledR}$ L 100 and Eudragit S 100 combinations. Drug Dev. Ind. Pharm. 26, 549-554.

6. Jalil, R. and Nixon, J.R. 1990. Microencapsulation using poly (dl-lactic acid) I: effect of preparative variables on the microcapsule characteristics and release kinetics. $J$. Microencap. 7, 229-244.

7. Lamprecht, A., Rodero, H.T., Schafer, U. and Michael, C.L. 2000. Biodegradable microspheres as a two-drug controlled release formulation: a potential treatment of inflammatory bowel disease. J. Controlled Release. 69, 445-454.

8. Jameela, S.R., Suma, N. and Jayakrishnan, A. 1997. Protein release from poly (e-caprolactone) microspheres prepared by melt encapsulation and solvent evaporation techniques: a comparative study. J. Biomater. Sci. Polymer Ed. 8, 457-466. 
9. Mandal, U., Gowda, V., Ghosh, A., Selvan, S., Soloman, S. and Pal, T. 2007. Formulation and optimization of sustained release matrix tablet of Metformin HCL $500 \mathrm{mg}$ using response surface methodology. Yakugaku Zasshi. 127, 12811290.

10. Venkatesan, P., Manavalan, R. and Valliappan, K. 2011. Preparation and evaluation of sustained release loxoprofen loaded microspheres. J. Basic. Clin. Pharma. 2, 159-162.

11. Akhter, S., Paul, S., Hasan, I., Ayon, N.J., Haider, S.S. and Reza, S. 2013. Preparation, characterization and compatibility studies of naproxen loaded microspheres of cellulosic and polymethacrylic polymeric blend. Dhaka Univ. J. Pharm. Sci. 12, 11-21.

12. Dharmalingam, S.R., Ramamurthy, S., Chidambaram, K. and Nadaraju, S. 2013. Development and validation of UV spectrophotometric method for the estimation of naproxen in bulk and semi-solid formulation. Int. J Ana. Pharm. \& Biomed. Sci. 2, 49-55.
13. Kannan, K., Karar, K.P. and Manavalan, R. 2009. Formulation and evaluation of sustained release microspheres of acetazolamide by solvent evaporation technique. J. Pharm. Sci \& Res. 1, 36-39.

14. Rojas, M., Leite, T., Cristianini, M., Alvim, I. and Augusto, P. 2016. Peach juice processed by the ultrasound technology: Changes in its microstructure improve its physical properties and stability. Food Research Int. 82, 22-33.

15. Patel, A.S., Soni, T.G., Thakkar, V.T. and Gandhi, T.R. 2011. Effect of polymeric blend on the dissolution behavior of spray-dried microparticles. Int. J. Res Pharm. \& Chem. 1, 690-701.

16. Naik, J., Lokhande, A., Mishra, S. and Kulkarni, R. 2013. Formulation and evaluation of gliapiazid loaded nanoparticles. Int. J. Pharm. Pharm. Sci. 5, 147-151.

17. Alhalaweh, A., Andersson, S. and Velaga, SP. 2009. Preparation of zolmitriptan-chitosan microspheres by spray drying for nasal delivery. Eur. J. Pharm. Sci. 38, 206-214. 